\title{
Comparison of Ventricular Refractory Periods Determined by Incremental and Decremental Scanning of an Extrastimulus
}

\author{
FRED MORADY, ALAN H. KADISH, JEFFREY A. KUSHNER, \\ LAURI K. TOIVONEN, and STEPHEN SCHMALTZ \\ From the Division of Cardiology and the Clinical Research Center, Department of Internal \\ Medicine, University of Michigan Medical Center, Ann Arbor, Michigan
}

\begin{abstract}
MORADY, F. ET AL.: Comparison of Ventricular Refractory Periods Determined by Incremental and Decremental Scanning of an Extrastimulus. This study compared the ventricular effective refractory periods measured by scanning diastole with an extrastimulus in incremental and decremental steps of 5 msec. The subjects of the study were 80 patients undergoing a clinically indicated electrophysiological test. Eight beat basic drive trains at a cycle length of $600 \mathrm{msec}$ and an intertrain pause of 4 seconds were used to measure the ventricular effective refractory period (VERP). In the incremetal method, the extrastimulus initially was positioned at a coupling interval shorter than the VERP and the coupling interval then was progressively increased until ventricular capture occurred. In the decremental method, the initial extrastimulus coupling interval was longer than the VERP and the coupling interval was progressively shortened until ventricular capture was lost. In 50 subjects, the mean VERP determined by the incremental method, $252 \pm 18$ ( \pm standard deviation), was significantly longer than the mean VERP determined in the same patients by the decremental method, $248 \pm 18 \mathrm{msec}(P<0.0001)$. In ten subjects, a subthreshold stimulus ( $S^{\prime}$ ) positioned $10 \mathrm{msec}$ earlier than the VERP had an inhibitory effect that lengthened the VERP by an average of $7 \mathrm{msec}$; however, when $S^{\prime}$ was positioned after the seventh beat of an eight beat drive train, no inhibitory effect could be demonstrated. In 20 subjects, VERP's were determined by the incremental and decremental methods using intertrain pauses of $1,4,8,12$, and 20 seconds. The mean VERP measured by the incremental method was significantly less than the mean VERP measured by the decremental method when the intertrain pause was 1, 4, or 8 seconds, but not when the pause was 12 or 20 seconds. The results of this study demonstrate that incremental scanning of an extrastimulus with eight beat basic drive trains yields a longer VERP than when the extrastimulus is scanned in decremental fashion. The discrepancy between the two methods is not attributable to inhibition by noncapturing extrastimuli in the incremental method, but rather to a decrease in the VERP caused by an effect of extrastimuli that capture the ventricle in the decremental method. Therefore, when a conventional eight beat drive train and 4 second intertrain pause are used to measure ventricular refractoriness, incremental scanning of an extrastimulus yields a more accurate VERP than does decremental scanning. (PACE, Vol. 12, April 1989)
\end{abstract}

ventricular refractory period, extrastimulus technique

\section{Introduction}

The conventional method for measuring the ventricular effective refractory period (VERP) in-

\footnotetext{
Address for reprints: Fred Morady, M.D., Division of Cardiology, University Hospital, 1500 East Medical Center Drive, UH B1 F245-0022, Ann Arbor, MI 48109-0022.

Received October 14, 1988; accepted November 1, 1988.
}

volves scanning diastole with a ventricular extrastimulus to identify the longest extrastimulus coupling interval that does not evoke a ventricular response. Conventionally, the extrastimulus is inserted initially at a coupling interval that exceeds the VERP and the extrastimulus coupling interval then is progessively shortened until ventricular capture is lost. ${ }^{1-4}$ Alternatively, the extrastimulus initially may be inserted at a coupling 
interval shorter than the VERP and the extrastimulus coupling interval then may be progressively lengthened until ventricular capture is obtained. Preliminary observations in this laboratory indicated that the two methods for measuring ventricular refractoriness may yield different results, suggesting the presence of hysteresis in the interval-excitability relationship.

The purpose of this study was to compare the VERP obtained by incremental and decremental scanning of an extrastimulus and to investigate the mechanism underlying the disparate results that may be obtained with the two methods for measuring ventricular refractoriness.

\section{Methods}

\section{Subjects Studied}

The subjects of this study were 80 patients who underwent a clinically-indicated electrophysiology test for evaluation of ventricular tachycardia, paroxysmal supraventricular tachycardia, or unexplained syncope. The selection criteria for subjects included the presence of sinus rhythm at a cycle length longer than $600 \mathrm{msec}$ and the absence of inducible ventricular tachycardia or supraventricular tachycardia by programmed stimulation with a single ventricular extrastimulus. We have observed that occasional patients may have a gap in ventricular capture during determination of ventricular refractoriness, with reproducible noncapture at a particular coupling interval and subsequent ventricular capture at a shorter coupling interval, ${ }^{5}$ such patients were excluded from this study. There were 60 men and 20 women, and their mean age was 51 \pm 16 years ( \pm standard deviation). Nineteen patients had coronary artery disease, nine patients had idiopathic dilated cardiomyopathy, six patients had hypertensive heart disease, and 46 patients had no identifiable structural heart disease. The left ventricular ejection fraction was determined by radionuclide or contrast ventriculography in 53 of 80 patients and was $0.48 \pm 0.10$.

\section{Electrophysiology Study}

Electrophysiology studies were performed in the fasting, unsedated state after informed consent was obtained and at least five half-lives after discontinuation of all antiarrhythmic drugs in- cluding beta-adrenergic blocking agents. Two to four quadripolar electrode catheters were positioned in the heart as clinically indicated. Leads $\mathrm{V}_{1}$, I, and III, and the intracardiac electrograms were recorded on a Siemens-Elema Mingograf 7 (Siemens-Elema, Solna, Sweden) recorder at a paper speed of $100 \mathrm{~mm} / \mathrm{sec}$. Bipolar pacing was performed with a programmable stimulator (Bloom Associates, Ltd., Narbeth, PA, USA) using stimuli $2 \mathrm{msec}$ in duration and twice the diastolic threshold.

\section{Measurement of the Ventricular Effective Refractory Period}

A stable catheter position was obtained at the right ventricular apex under fluoroscopic guidance. The VERP was measured using an eight beat drive train at a cycle length of $600 \mathrm{msec}$. If there was not one-to-one ventriculoatrial conduction during basic drive, the atrium and ventricle were paced simultaneously to prevent interruption of the basic drive train by a sinus capture beat. The delay between the first beat of the basic drive train and the preceding sinus beat was fixed at 600 msec.

The incremental method for determining the VERP period consisted of inserting an extrastimulus at an initial coupling interval of 180 to 200 msec, which was shorter than the VERP and did not result in ventricular capture. The coupling interval was increased in steps of $5 \mathrm{msec}$ and each coupling interval was repeated once to confirm noncapture. The extrastimulus coupling interval was increased until ventricular capture occurred.

The decremental method for determining the VERP consisted of inserting an extrastimulus at an initial coupling interval of 280 to $300 \mathrm{msec}$, which was longer than the VERP and resulted in ventricular capture. The coupling interval was decreased in steps of $5 \mathrm{msec}$ until ventricular capture no longer occurred.

In both methods for measuring ventricular refractoriness, the VERP was defined as the longest extrastimulus coupling interval that reproducibly failed to evoke a ventricular depolarization.

\section{Study Protocol}

The purpose of the first part of this study was to quantitate the difference in VERP determined 
by the incremental and decremental methods. The VERP was determined by both methods in 50 subjects. An intertrain interval of 4 seconds was used because this is typical of the intertrain pause used when measuring refractory periods in many clinical electrophysiology laboratories. The VERP was determined first by the incremental method. Upon ventricular capture, the extrastimulus coupling interval was increased by $10 \mathrm{msec}$ and the VERP was determined again by the decremental method.

The mean VERP measured by the decremental method was found to be shorter than the mean VERP measured by the incremental method in the 50 subjects in the first part of the study, and the purpose of the second part of this study was to determine the reason for this difference. The subjects of the second part of the study were 30 patients who did not have spontaneous or induced atrial or ventricular premature depolarizations. This additional selection criterion was imposed to avoid the possible confounding effects of premature depolarizations.

One possible reason for the difference in VERP determined by the incremental and decremental methods was a relative lengthening of the VERP with the incremental method because of an inhibitory effect of noncapturing extrastimuli that preceded the first extrastimulus that captured the ventricle. The possibility that noncapturing extrastimuli might exert an inhibitory effect that persists for more than just one beat was evaluated in ten subjects. The VERP was determined by the decremental method using a 4 second pause between basic drive trains. An extrastimulus (S) at a coupling interval $10 \mathrm{msec}$ shorter than the VERP then was inserted after the eighth beat of the basic drive train and the ventricular effective refractory period was determined again. The VERP was determined a third time with $S^{\prime}$ positioned after the seventh beat of the eight beat basic drive train.

A second possible reason for the difference in VERP determined by the incremental and decremental methods was a relative shortening of the VERP with the decremental method because of an effect of preceding extrastimuli that resulted in ventricular capture. It was hypothesized that if the extrastimuli that preceded the VERP and resulted in ventricular capture in the decremental method were responsible for shortening the VERP relative to the incremental method, the difference in VERP would be accentuated when the intertrain pause was shortened and attenuated when the intertrain pause was lengthened. This hypothesis was tested in 20 subjects by determining the VERP using the incremental and decremental methods with intertrain intervals of $1,4,8,12$, and 20 seconds.

In these 20 subjects, the VERP were determined first by scanning the extrastimulus in incremental fashion, then in decremental fashion. Therefore, the VERP determined by the decremental method was preceded by a larger number of basic drive trains. Because the basic drive train may have a cumulative effect on ventricular refractoriness, ${ }^{6.7}$ the sequence in which the two methods were performed potentially may have influenced the results. To evaluate this possibility, the VERP's also were determined in reverse order (decremental method, then incremental method) after a 2 minute rest period in 10 of these 20 subjects, using intertrain pauses of 1 and 4 seconds.

\section{Measurement of Ventricular Effective Refractory Periods Using a Three Minute Basic Drive Train}

When there is an increase in rate, a drive train duration of greater than 50 beats often is necessary before the maximum shortening in ventricular refractoriness is attained. ${ }^{6,7}$ At a basic drive cycle length of 600 msec, a steady-state VERP is achieved by 3 minutes of pacing, and this steady-state VERP is an average of $12 \mathrm{msec}$ shorter than the VERP determined with an eight beat basic drive train. ${ }^{8}$ In the 20 subjects in whom the VERP's were determined using intertrain pauses of 1-20 seconds, the VERP was also measured with a basic drive train duration of $3 \mathrm{~min}$ utes, to determine whether the steady-state VERP also is influenced by the method used to scan the extrastimulus. After 3 minutes of continuous ventricular pacing at a cycle length of $600 \mathrm{msec}$, an extrastimulus was inserted after every eighth paced beat at an initial coupling interval of 180 msec and with no interruption in the basic drive train. The extrastimulus was scanned in incremental fashion until ventricular capture oc- 
curred. The extrastimulus then was scanned in decremental fashion to determine the VERP by the decremental method.

\section{Analysis of Data}

The VERP's measured by the incremental and decremental methods in the 50 patients in the first part of this study were compared with a paired Student's t-test. The effects of subthreshold stimuli and intertrain pauses of varying duration on the VERP were analyzed using a repeated measures analysis of variance. ${ }^{9}$ Multiple comparisons were performed using Fjsher's least significant difference procedure. ${ }^{9} \mathrm{~A} P$ value less than 0.05 was considered significant.

\section{Results}

\section{Ventricular Effective Refractory Periods Determined by the Incremental and Decremental Methods}

In 50 subjects, the mean VERP determined by decremental scanning of an extrastimulus, 248 $\pm 18 \mathrm{msec}$, was significantly shorter than the mean VERP determined by incremental scanning of an extrastimulus, $252 \pm 18 \mathrm{msec}(\mathrm{P}<0.0001)$. The VERP measured by the decremental method was 5 msec shorter than the VERP measured by the incremental method in 24 subjects, $10 \mathrm{msec}$ shorter in three subjects, and $15 \mathrm{msec}$ shorter in one subject. The two methods yielded the same VERP in 21 subjects, and in one subject the VERP determined by the decremental method was 5 msec longer than the VERP determined by the incremental method.

There was no significant difference in the mean baseline spontaneous cycle length between the 28 subjects in whom the decremental method yielded a shorter VERP than the incremental method ( $823 \pm 124 \mathrm{msec}$ ) and the 22 subjects in whom it did not $(797 \pm 146 \mathrm{msec})$.

\section{Inhibition by Subthreshold Stimuli}

In the presence of a noncapturing extrastimulus $\left(S^{\prime}\right)$ positioned after the last beat of the basic drive train at a coupling interval $10 \mathrm{msec}$ shorter than the VERP, the VERP determined by the decremental method in ten subjects increased by a mean of $7 \pm 4 \mathrm{msec}(\mathrm{P}<0.001)$. However, when $S^{\prime}$ was positioned after the seventh beat of
Table I.

Inhibition by a Subthreshold Extrastimulus ( $\mathrm{S}^{\prime}$ )

\begin{tabular}{rccc}
\hline & \multicolumn{3}{c}{ VERP (ms) } \\
\cline { 2 - 4 } Subject & Control & $\begin{array}{c}\text { S' after } \\
\text { 8th } \mathbf{S}_{\mathbf{1}}\end{array}$ & $\begin{array}{c}\text { S' after } \\
\text { 7th } \mathbf{S}_{\mathbf{1}}\end{array}$ \\
\hline 1 & 235 & 240 & 235 \\
2 & 285 & 230 & 285 \\
3 & 250 & 260 & 250 \\
4 & 225 & 235 & 225 \\
5 & 220 & 225 & 220 \\
6 & 220 & 225 & 220 \\
7 & 255 & 255 & 250 \\
8 & 200 & 205 & 200 \\
9 & 250 & 260 & 250 \\
10 & 240 & 245 & 240 \\
Mean & 238 & $245^{+}$ & $238^{*}$ \\
\pm SD & \pm 24 & \pm 26 & \pm 23 \\
\hline
\end{tabular}

$+p<0.001$ vs. control

- No significant difference vs. control

Abbreviations: $S_{1}=$ basic drive beat, $S D=$ standard deviation; VERP $=$ ventricular effective refractory period

the eight beat drive train, the mean VERP was not significantly different than the mean VERP determined in the absence of $S^{\prime}$ (Table I).

\section{Effects of the Intertrain Pause}

The mean VERP determined by the incremental and decremental methods in 20 subjects using intertrain pauses of $1,4,8,12$, and 20 seconds are listed in Table II. The mean VERP determined by the incremental method was significantly longer than the mean VERP determined by the decremental method when the intertrain pause was 1,4 , and 8 seconds, but not when the pause was 12 or 20 seconds. Data from the individual subjects are displayed in Figure 1. When the intertrain pause was 1 second, the VERP determined by the incremental method exceeded the VERP determined by the decremental method in all but two subjects. As the duration of the intertrain pause lengthened, the number of subjects in whom the two methods yielded the same VERP increased.

In ten subects, the mean VERP determined by the incremental and decremental methods were not significantly influenced by the sequence in which the two methods were applied. 
Table II.

Ventricular Refractory Periods Determined in 20 Subjects Using Intertrain Pauses of 1-20 Seconds

\begin{tabular}{cccc}
\hline & \multicolumn{2}{c}{ VERP (ms) } & \\
\cline { 2 - 3 } Pause & $\begin{array}{c}\text { Incremental } \\
\text { (seconds) }\end{array}$ & $\begin{array}{c}\text { Mecremental } \\
\text { Method }\end{array}$ & P Value \\
\hline 1 & $236 \pm 20^{+}$ & $230 \pm 19$ & $<0.001$ \\
4 & $236 \pm 19$ & $234 \pm 19$ & $<0.001$ \\
8 & $239 \pm 19$ & $238 \pm 19$ & $<0.01$ \\
12 & $241 \pm 19$ & $241 \pm 19$ & NS \\
20 & $242 \pm 20$ & $242 \pm 20$ & NS \\
\hline
\end{tabular}

+ Mean \pm standard deviation

Abbreviations: NS $=$ not significant. Other abbreviations as in Table 1.

The VERP determined by both the incremental and decremental methods increased significantly as the intertrain pause was lengthened from 1 to 12 seconds $(P<0.001)$, with no further increase when the pause was lengthened from 12 to 20 seconds. The mean spontaneous cycle length during the intertrain pauses was not significantly different during the incremental method versus the decremental method.

\section{Ventricular Effective Refractory Periods Determined After Three Minutes of Basic Drive}

When VERP's were determined after 3 minutes of basic drive with no pause following the extrastimulus, the mean VERP measured by the incremental and decremental methods did not differ significantly $(221 \pm 20$ and $221 \pm 21 \mathrm{msec}$, respectively; $P>0.05$ ). These mean VERP's were significantly shorter than the mean VERP determined in the same 20 subjects using an eight beat drive train and an intertrain pause of 1 to 20 seconds $(P<0.001$ for comparisons of 3 minute values with each of the values in Table II).

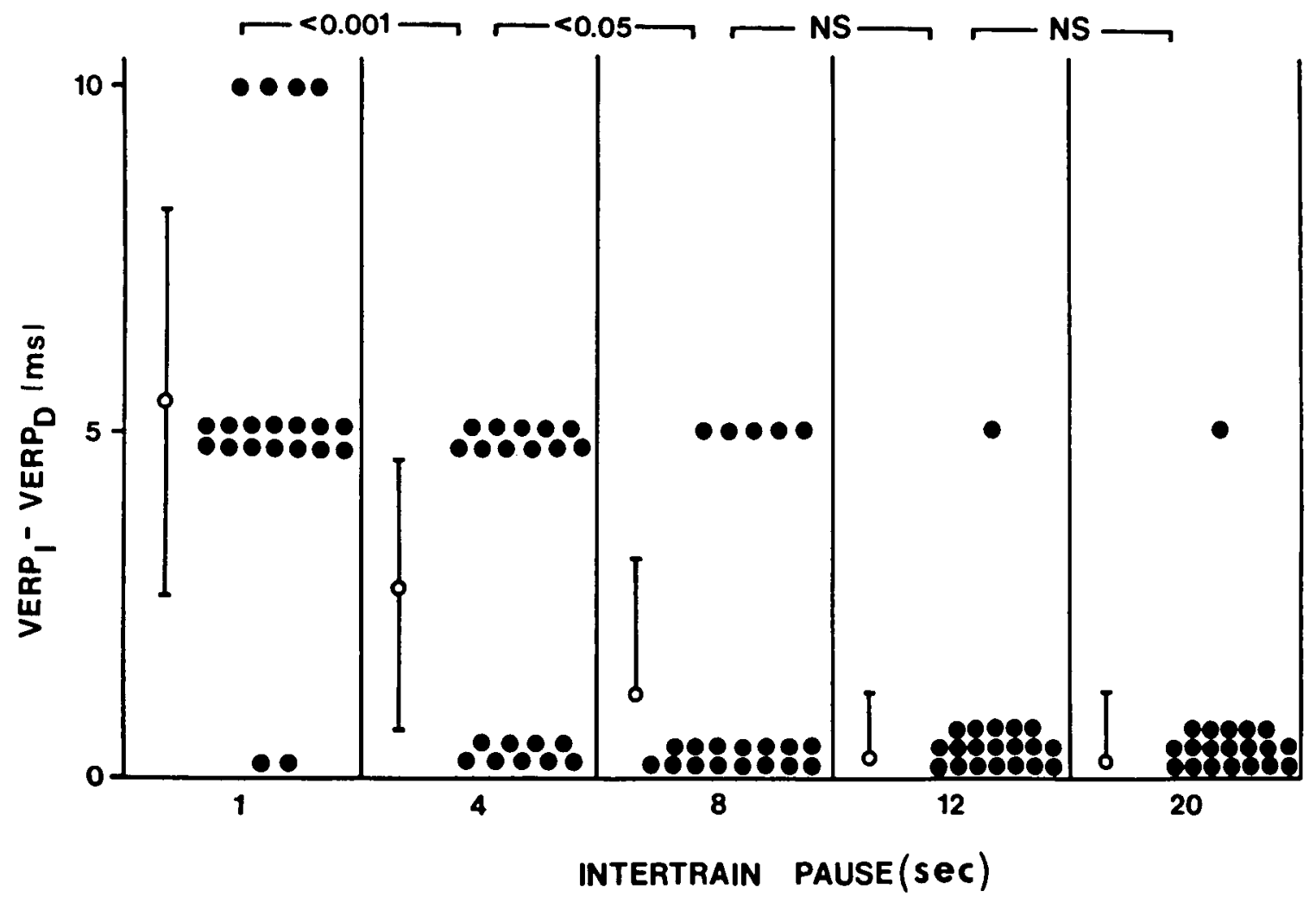

Figure 1. The effect of the duration of the intertrain pause on the difference in ventricular effective refractory periods measured by the incremental and decremental methods (VERP I $^{-}$ VERP $P_{\mathrm{D}}$ ) in 20 subjects. 


\section{Discussion}

\section{Incremental Versus Decremental Scanning of an Extrastimulus}

When diastole is scanned with an extrastimulus to determine the VERP, the extrastimulus may be scanned in either an incremental or decremental fashion. The results of this study demonstrate that the VERP measurement that is obtained may be influenced by the direction in which the extrastimulus is scanned. Incremental scanning of an extrastimulus starting at a coupling interval shorter than the VERP often yields a value for the VERP that is longer than when the extrastimulus is scanned in decremental fashion starting at a coupling interval that exceeds the VERP. When the VERP is determined using a conventional eight beat basic drive train at a cycle length of $600 \mathrm{msec}$ and a 4 second intertrain pause, the VERP determined by the incremental method is $\geq \mathbf{5} \mathrm{msec}$ longer than the VERP determined by the decremental method in $56 \%$ of patients, and $\geq 10 \mathrm{msec}$ longer in $8 \%$ of patients.

\section{Possible Mechanisms}

Because the basic drive train has a cumulative shortening effect on ventricular refractoriness when there is an acceleration in rate ${ }^{6-8}$ the sequence in which the incremental and decremental methods are applied theoretically might explain differences in the VERP measurements obtained by the two methods. However, this possibility may be ruled out as the explanation for the disparate results obtained with the two methods, because the sequence in which incremental and decremental scanning was performed did not influence the VERP measurements.

In considering possible explanations for the discrepancy in VERP obtained by the incremental and decremental methods, the only apparent difference between the two methods is that in the incremental method, eventual ventricular capture by the extrastimulus is preceded by extrastimuli that do not result in ventricular capture, whereas in the decremental method, eventual loss of ventricular capture by the extrastimulus is preceded by extrastimuli that do capture the ventricle. Therefore, it seemed likely that the difference in VERP determined by the incremental and decremental methods was attributable to some effect of the extrastimuli that preceded the extrastimulus that defined the VERP. In the incremental method, preceding extrastimuli that did not capture the ventricle may have resulted in a relative lengthening of the VERP, or alternatively, in the decremental method, preceding extrastimuli that captured the ventricle may have resulted in a relative shortening of the VERP.

\section{Inhibition by Noncapturing Extrastimuli}

Previous studies have demonstrated that subthreshold extrastimuli that occur within the VERP may prolong ventricular refractoriness. ${ }^{10,11}$ Therefore, the noncapturing extrastimuli that occurred in the incremental method potentially may have accounted for relative lengthening of the VERP by an effect of inhibition. However, in previous studies, the subthreshold extrastimuli that resulted in inhibition always were positioned in close temporal proximity to the extrastimulus used to define the VERP. ${ }^{10.11}$ In contrast, in the present study, subthreshold extrastimuli would have had to exert an inhibitory effect that persisted for the duration of the intertrain pause and the next eight beat basic drive train in order to account for a lengthening of the VERP with the incremental method for measuring ventricular refractoriness.

Evaluation of the inhibitory effects of subthreshold extrastimuli in this study demonstrated that the noncapturing extrastimuli that occur in the course of measurement of ventricular refractoriness by the incremental method do not lengthen the VERP. Whereas the phenomenon of inhibition consistently was demonstrated when a subthreshold extrastimulus was positioned immediately prior to the extrastimulus used to measure the VERP, this inhibitory effect was lost completely when the subthreshold extrastimulus was separated by a single basic drive beat from the extrastimulus used to measure the refractory period. These results indicate that a subthreshold extrastimulus positioned within the VERP does not exert any effects that persist beyond the cycle in which it occurs. Therefore, the longer VERP that may be measured with the incremental method compared to the decremental method cannot be attributed to an inhibitory effect of 
noncapturing extrastimuli in the incremental method.

\section{Shortening of Ventricular Refractoriness by Extrastimuli}

Ventricular refractoriness responds in dynamic fashion to a change in heart rate, and when there is either an abrupt increase or decrease in rate, up to several minutes may be required before a new steady-state ventricular refractory period is attained.

An extrastimulus that is $10-20 \mathrm{msec}$ longer than the VERP serves to abruptly increase the rate for one cycle, thereby shortening ventricular refractoriness. Immediately after the extrastimulus, the rate abruptly slows again and ventricular refractoriness increases. However, depending on how quickly ventricular refractoriness adapts to a sudden decrease in rate and on the interval between extrastimuli, it is possible that the shortening effect of an extrastimulus on ventricular refractoriness may not be completely dissipated by the time the next extrastimulus is introduced. Therefore, it was considered possible that decremental scanning of an extrastimulus yields a shorter VERP than does the incremental method because of a residual shortening effect of extrastimuli that result in ventricular capture before the VERP is reached. If this were the case, the difference in VERP measured by the incremental and decremental methods would be influenced by the interval separating extrastimuli. This hypothesis was tested by comparing the VERP obtained by the incremental and decremental methods using intertrain pauses varying from 1 to 20 seconds.

The results of this study demonstrate that the difference in VERP measured by the incremental and decremental methods is a function of the intertrain pause. The difference is greatest when the intertrain pause is 1 second, and the magnitude of the difference progressively diminishes as the intertrain pause lengthens to 4 and 8 seconds. When the intertrain pause is 12 seconds or more, there is no longer a difference in the VERP determined by the incremental and decremental methods. Progressive diminution in the difference in the VERP's determined by the two methods as the intertrain pause increases is con- sistent with the hypothesis that the difference between the two methods is attributable to shortening of ventricular refractoriness by the extrastimuli that evoke ventricular capture during decremental scanning of an extrastimulus. Therefore, in the conventional method for determining the VERP by decremental scanning of an extrastimulus, the extrastimulus used to measure refractoriness may itself shorten refractoriness.

\section{Presumed Effects on Action Potential Duration}

Changes in action potential duration underlie the effects of a change in rate on refractoriness. ${ }^{7}$ Therefore, the observation that decremental scanning of an extrastimulus often yields a shorter VERP than the incremental method when the intertrain pause is less than 8 seconds implies that a sudden increase in rate for even one cycle often may have an effect on action potential duration that persists for several seconds after the rate has again slowed. Additional studies utilizing a catheter to record monophasic action potential duration $^{12}$ may be helpful in better defining the time course of recovery of the action potential from the effects of a sudden increase in rate that lasts for only one cycle.

Of note is that within individual subjects, there was not a significant difference in the spontaneous cycle length during the intertrain pauses between the incremental and decremental methods for measuring the VERP. Therefore, a relative shortening of the VERP with the decremental method cannot be attributed to an effect of extrastimuli that capture the ventricle on the sinus cycle length.

\section{Measurement of Ventricular Refractoriness with a Basic Drive Train Duration of Three Minutes}

When the basic drive cycle length is 600 $\mathrm{msec}$, the steady-state VERP is an average of 12 msec shorter than the VERP measured with the conventional eight beat basic drive $\operatorname{train}^{8} \mathrm{~A}$ steady-state VERP is present after 3 minutes of continuous pacing, ${ }^{8}$ and therefore the incremental and decremental methods for measuring the VERP were compared after three minutes of pacing at a cycle length of $600 \mathrm{msec}$ and without interruption in the basic drive train, in order to 
determine whether the difference in VERP that exists when the basic drive train is eight beats is also present under steady-state conditions.

When the basic drive train duration was 3 minutes, there was not a difference in the VERP's obtained by incremental and decremental scanning of an extrastimulus. This finding suggests that under steady-state conditions, after the maximum effect of an increase in rate has been achieved during basic drive, an extrastimulus that abruptly increases the rate for one cycle has less of an effect on ventricular refractoriness than when the basic drive train is eight beats and an intertrain pause is used. The pertubation in ventricular refractoriness that is caused by an extrastimulus that captures the ventricle appears to be either smaller in magnitude or shorter in duration under steady-state conditions than when an extrastimulus is introduced during the conventional decremental method for measuring refractoriness.

It should be noted that diastole was scanned by an extrastimulus in steps of $5 \mathrm{msec}$ in this study. The possibility exists that a difference in the VERP's measured by the incremental and decremental methods would have been detected even under steady-state conditions had diastole been scanned in steps less than 5 msec.

\section{Effects of the Intertrain Pause on Measurement of the VERP}

As expected, because of a cumulative effect of the basic drive train on ventricular refractoriness, the VERP measured after 3 minutes of continuous pacing and without a pause after the extrastimuli was significantly shorter that the VERP determined with an eight beat drive train and an intertrain pause of 1 second. However, progressive lengthening of the intertrain pause was asso-

\section{References}

1. Marchlinski FE. Characterization of oscillations in ventricular refractoriness in man after an abrupt increment in heart rate. Circulation 1987; 75:550556.

2. Swerdlow CD, Liem LB, Franz MR. Summation and inhibition by ultrarapid train pacing in the human ventricle. Circulation 1987; 76:1101-1109.

3. Stevenson WG, Wiener I, Weiss JN. Effect of spa- ciated not only with equalization of the VERP's measured by the incremental and decremental methods, but also with a progressive increase in the VERP up to an intertrain pause of 12 seconds. These results indicate that the cumulative effect of the basic drive train on ventricular refractoriness is attenuated but still present when the basic drive train is interrupted by pauses of 1 to 8 seconds. Only when the intertrain pause is $12 \mathrm{sec}$ onds or more is there no longer any evidence of a cumulative effect of the basic drive train on ventricular refractoriness.

\section{Conclusions}

In conclusion, when measuring ventricular refractoriness under steady-state conditions after prolonged and continuous pacing, the same VERP measurement is obtained regardless of the direction in which the extrastimulus is scanned. However, when the VERP is measured by a conventional method using a basic drive train of eight beats and an intertrain pause of 4 seconds, a more accurate determination of the VERP is obtained if the extrastimulus is initially positioned at a coupling interval shorter than the VERP and then scanned in incremental steps until ventricular capture is obtained. The standard technique of scanning diastole in decremental steps with an extrastimulus until ventricular capture is lost introduces an error into the measurement of refractoriness, because the extrastimulus being used to measure refractoriness may itself shorten refractoriness.

Acknowledgment: The authors gratefully acknowledge the technical assistance of Beverly Burgie, Joan Bergeron, and Linda Abbott and the secretarial assistance of Lisa Hackbarth and Judy Hanson. 
tricular excitability-interval relationship in early diastole in humans (Submitted).

6. Janse MJ, van der Steen ABM, van Dam RT, et al. Refractory period of the dog's ventricular myocardium following sudden changes in frequency. Circ Res 1969; 24:251-262.

7. Boyett MR, Jewell BR. Analysis of the effects of changes in rate and rhythm upon electrical activity in the heart. Prog Biophys Molec Biol 1980; 36:1-52.

8. Morady F, Kadish AH, Toivonen LK, et al. The maximum effect of an increase in rate on ventricular refractoriness. PACE (In press).

9. Milliken GA, Johnson DE. Analysis of Messy Data.
Volume 1: Designed Experiments. New York, Van Nostrand Reinhold Company, 1984, 322-350.

10. Prystowsky EN, Zipes DP. Inhibition in the human heart. Circulation 1983; 68:707-713.

11. Stevenson WG, Wiener I, Weiss J, et al. Limitations of bipolar and unipolar conditioning stimuli for inhibition in the human heart. Am Heart J 1987; 114:303-310.

12. Franz MR, Bargheer K, Rafflenbeul W, $t$ al. Monophasic action potential mapping in human subjects with normal electrocardiograms: Direct evidence for the genesis of the $T$ wave. Circulation $1987 ; 75: 379-386$. 
This document is a scanned copy of a printed document. No warranty is given about the accuracy of the copy. Users should refer to the original published version of the material. 